\title{
Speech-language therapy for adolescents with written- language difficulties: The South African context
}

D Erasmus, B Communication Pathology; L Schutte, B Communication Pathology; M van der Merwe, B Communication Pathology; S Geertsema, M Communication Pathology

Department of Communication Pathology, University of Pretoria, Gauteng, South Africa

Corresponding author: S Geertsema (salome.geertsema@up.ac.za)

\begin{abstract}
Objective. To investigate whether privately practising speech-language therapists in South Africa are fulfilling their role of identification, assessment and intervention for adolescents with written-language and reading difficulties. Further needs concerning training with regard to this population group were also determined.

Method. A survey study was conducted, using a self-administered questionnaire. Twenty-two currently practising speech-language therapists who are registered members of the South African Speech-Language-Hearing Association (SASLHA) participated in the study.

Results. The respondents indicated that they are aware of their role regarding adolescents with written-language difficulties. However, they feel that South-African speech-language therapists are not fulfilling this role. Existing assessment tools and interventions for written-language difficulties are described as inadequate, and culturally and age inappropriate. Yet, the majority of the respondents feel that they are adequately equipped to work with adolescents with written-language difficulties, based on their own experience, self-study and secondary training. The respondents feel that training regarding effective collaboration with teachers is necessary to establish specific roles, and to promote speechlanguage therapy for adolescents among teachers.

Conclusion. Further research is needed in developing appropriate assessment and intervention tools as well as improvement of training at an undergraduate level.
\end{abstract}

Keywords: speech-language therapist, adolescents, written difficulties, current practice, perceptions, needs, training, South African context

S Afr J CD 2013;60:50-58 DOI:10.7196/SAJCD.87

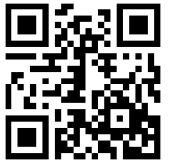

The International Reading Association's Commission on Adolescent Literacy (Moore, Bean, Birdyshaw \& Rycik, 1999) states that 21st century adolescents will be required to read and write more when entering the adult world. Future literacy needs of adolescents are complex and demanding; therefore serious and continuing attention is needed in the development of their reading, writing and language skills (Kathard et al., 2011).

With age, literacy difficulties increasingly affect adolescents, which can lead to reduced competence and confidence in adulthood. This compromises their life and work trajectories (Harreveld, Baker \& Isdale, 2008). A common concern is that adolescents do not develop the adequate writing skills needed for academic and vocational success and success in their personal lives (Kathard et al., 2011). The effect that reading and writing disabilities have on students' transition into adult life is seldom addressed (Sitlington, 2008). Most adolescents who have learning disabilities not only present with reading deficits, but also with deficits in other academic areas such as writing (Geertsema, Hyman \& Van Deventer, 2011; Shumaker \& Deshler, 2003).

Owens (2010) further categorises written-language difficulties into dyslexia (a disorder of reading characterised by poor reading comprehension or word-recognition abilities), and dysgraphia (difficulty in writing including spelling errors, punctuation, word omissions, agrammatical sentences, substitution and lack of organisation). Dyslexia and dysgraphia are distinguished from nonspecific reading disorders, on the grounds of their characteristic problems with decoding and encoding (Jantzen, 2010; Stark, 2010). These decoding and encoding problems can be described in terms of dyslexia, discalculia (a mathematical learning problem), and Gertsmann syndrome (poor spatial orientation) (Stark, 2010). Nonspecific reading difficulties are differentially distinguished from dyslexia on the basis of possible low intelligence, poor motivation, perceptual and sensory problems, emotional problems, socialcultural factors, educational deprivation, attention deficit disorder (ADD), attention deficit hyperactivity disorder (ADHD), or a second-language learning barrier (Stark, 2010). Factors leading to non-specific writing difficulties may range from difficulties with the execution and regulation of the processes that underlie proficient composing to motivational factors (Stark, 2010). Children experiencing these difficulties display shorter written texts, are more prone to grammatical or spelling errors, and have poor organisational skills (Owens, 2010).

Literacy skills are essential for people to achieve maximum functional participation throughout their foundation-phase school years into adulthood, and are prerequisites for employment as well as quality of life (ASHA, 2001). Many children and adolescents, growing up in deprived socioeconomic environments, are at risk of poor oral language and general communication skills (Kathard et al., 2011). Spoken and written language are strongly linked in terms of the physiology of the reading (decoding) and writing (encoding) processes (Stark, 2010). Phonetic decoding abilities (word attack strategies) as well as eidetic deciphering (look-and-say strategies) rely strongly on an individual's vocabulary. This poses a risk in terms of second-language learning barriers, and cognitive academic language proficiency in general. These risks are aggravated by the current socioeconomic and educational situation in South Africa (Kathard et al., 2011; Jordaan, 2011).

South Africa has one of the most diverse multilingual and multicultural populations in the world (Seeff-Gabriel, 2003). The language of learning and teaching (LoLT) in schools differs in many cases from home languages spoken and understood by learners. The term 'additional language' as opposed to 'second language' is preferred, as many South African children are exposed to more than one language in the home and community (Jordaan, 2011). Many studies in South Africa have shown English additional language (EAL) learners to display poorer phonological awareness skills than those of their English first language (EFL) peers (Seeff-Gabriel, 2003). These poor phonological awareness skills impact on learners' basic cognitive academic skills. The result is poorer pronunciation, and negative influences on their reading and spelling skills in the class context, where the LoLT is English (Pijper, 2003). Additional-language learning barriers can also mask the differential diagnosis of dyslexia and nonspecific reading and writing problems, because of the many additional factors at play (Stark, 2010). The education system in South Africa also poses certain challenges. The discontinued outcomes-based education 
system (OBE) is said to have contributed to the high school failure rate. Naki (2010) stated that school pass rates have dropped from a $60 \%$ average to about $40 \%$ average in rural areas, since the onset of the OBE system. Literacy and numeracy skills have been rated as some of the weakest in the world, as a result of underqualified educators as well as a lack of learning resources (Naki, 2010). However, these are not the only factors contributing to the academic situation. The role of language in education, peer-interaction as a social construct during language learning, and content- and language-integrated learning are often overlooked. Jordaan (2011) summarises these challenges as limited language awareness, inadequate teaching methods, the essentially positivist nature of $\mathrm{OBE}$ and weak integrated learning contexts.

In addressing some of the challenges, the newly introduced Curriculum and Assessment Policy Statements (CAPS) mark 'an important step to a basic education sector that is more unified, accountable, better informed about itself and more focused on workable solutions' (Soobrayan cited in Department of Basic Education; Notice 752 of 2010, p.4). The CAPS Action plan to 2014 acknowledges the need for improvement of all learning outcomes and proposes to introduce quality early childhood development, improve quality of teaching and learning, undertake regular assessments to track progress, and ensure an outcomes-focused planning and accountability system. More compulsory time spent on English in the foundationphase classroom of the EAL learner, constant numeracy and literacy progress tracking, attainment of minimum language and mathematics competencies in grades 6 and 9, and eventually increasing the number of grade 12 learners eligible for a university Bachelor's programme, are among the 13 proposed goals looking at learning outcomes and coverage (Department of Basic Education, 2010).

For a learner to access education, the ability to participate in active and interactive communication with peers as well as with adults in the classroom is necessary. Speech-language therapists play a critical role in the development of literacy when a child or adolescent displays communication difficulties. This role is implemented in collaboration with other experts in the field of the development of written language (ASHA, 2001). The written-language component of literacy is not explored by many speech-language therapists in the secondary school context. A study by Ehren and Ehren (2001) indicated that many speech-language therapists do not think that the assessment and intervention of written language is their role at the secondary school level. Speech-language therapists may be reluctant to assume roles regarding reading and writing for a variety of reasons such as their own perceptions, fear of change, and lack of training (Ehren \& Ehren, 2001). In addition to this, standardised tests with adequate validity and norms are not always available for adolescents (Adams, 2002). In a more recent study Wellman (2006) of the University of Cincinnati (USA) suggested that educator collaboration with speech-language therapists exists in supporting secondary school learners with reading problems, but many educators still hold a more traditional view of speech-language therapists as working only with speech sound production. Wellman (2006) suggested that educators and speechlanguage therapists are not in agreement regarding the roles of the school-based speech-language therapist pertaining to literacy, as put forth by ASHA (2001)

In South Africa, very few tests are available to cater for the 11 official languages, and even if assessment material such as the African receptive-expressive tests compiled in the South African Language Assessments Manual (Bortz, 1997) are administered, the examiner should preferably be a first-language speaker of the test being administered. Only when assisted by a first-language speaker, may an Afrikaans or English speaker administer the test (Bortz, 1997). Specific diagnostic tests for dyslexia are also much needed, and only recently has an Afrikaans dyslexia test entered our system (Stark, 2010).

Although many locally relevant studies indicate a willingness to collaborate, support and provide services to primary schools (Kathard et al., 2011; Moodley, Chetty, \& Pahl, 2005), there is a dearth of knowledge regarding the South African adolescent population. To be a role player in the Department of Basic Education's immediate 'Action plan to 2014' (Department of Basic Education, 2010), the speech-language therapist in South Africa has to answer a few questions regarding expected competencies and our role in the enhancement of language, learning and literacy in Basic Education. Issues to consider are the type of service delivery models, support in the development of all languages (including English as an additional language), and leadership and participation roles in social innovation (Kathard et al., 2011).

Therapy that addresses the underlying language problems in adolescents should be the primary role of the speech-language therapist at secondary school level. If language disabilities persist beyond the age of 8 - 10 years, it is no longer perceived to be the educator's responsibility to address the residual effects (Owens, 2010). Recent studies indicate that many such residual and persistent effects can occur into adolescence (Rescorla, 2008). According to Geertsema et al. (2011) written-language challenges, such as SMS (short message system) language occurring in the adolescent age group, are usually addressed by the educators themselves. However, the educators in their study perceived the role of the speech-language therapist to be one of assessment of and intervention in spelling errors, and sentence length and complexity. Learners should also be supported in the application of specific skills in order to construct meaning from spoken and written language (Staskowski \& Creaghead, 2001). A greater focus on, and understanding of, the needs of adolescents as they progress through their secondary school education is needed for this support (Bercow, 2008).

There is currently an internationally increased focus on the constant development of the language and communication skills of adolescents throughout their secondary school education (Vance \& Clegg, 2010). If an educator notices a learner who shows signs of poor academic performance due to a possible learning difficulty, referral to a speechlanguage therapist should be made (ASHA, 2001). However, Wellman (2006) suggested that there is no significant relationship between the educators' perceived roles of the speech-language therapist working in USA schools and their referral practices. Geertsema et al. (2011) found that educators in the South African secondary school system perceive the role of the speech-language therapist to be one of addressing written-language difficulties in the adolescent age group. This perception is in agreement with the roles and responsibilities as set forth by ASHA (2001) and SASHLA (2013). Furthermore, these educators represent the main source of referral within a system of collaboration in the secondary schools (Kathard et al., 2011).

Evidence-based practice within a population that is often neglected is warranted (Geertsema et al., 2011; Kathard et al., 2011; Rescorla, 2008). As school-based speech-language therapists in South Africa are generally employed in schools for learners with special educational needs (LSEN), and these populations exclude learners with average to above-average IQs such as learners with dyslexia, the current study focused on services provided to learners in mainstream secondary schools by private-practising speech-language therapists. Furthermore, the presence of many EAL learners in the historical Model C schools in the middle-class socio-economic group has increased the caseload of these learners among private practices in suburban areas.

\section{Methods \\ Objectives}

The main aim of this study was to describe the services provided to adolescents with written-language disabilities by private-practising speech-language therapists in South Africa.

The three objectives were to describe:

- Current practices of speech-language therapists in South Africa regarding the assessment of and intervention in written-language skills of adolescents

- Perceptions of speech-language therapists in South Africa regarding their role in assessment and intervention for written-language difficulties in adolescents

- The nature of speech-language therapists' needs in future training, andspecific training skills needed for assessment and intervention for this population.

\section{Research design}

This was a survey study which aimed to develop hypotheses in such a manner that more accurate investigation may occur at a later time. Within the exploratory research design, a self-administered 
questionnaire was utilised to research a larger population and more extended geographical region, ensuring a high degree of freedom and anonymity (Leedy \& Ormrod, 2005)

\section{Participants}

The target population was speech-language therapists in South Africa in private practice. A stratified, purposive probability sampling technique was used. This study only included those speech-language therapists currently in private practice, and the group of respondents was further divided into specific areas of practice. Respondents needed to meet the criterion of being actively in private practice - therefore registered with the Health Professions Council of South Africa (HPCSA) - before being eligible for inclusion in the sample. The SASHLA 2009 membership list was used to obtain the names and contact details of all the currently private-practising speech-language therapists in South Africa. Each member on this list was invited to participate in the study.

\section{Biographical profile of respondents}

Ten of the respondents (45\%) indicated that they graduated from the University of Pretoria, 23\% from the University of Cape Town, and 18\% from the University of the Witwatersrand. One respondent graduated from the University of Stellenbosch, one from the University of KwaZulu-Natal, and one from a university not situated in South Africa. Of the 22 respondents, 14 indicated that their highest qualification is an undergraduate degree in speech-language therapy and they represented $64 \%$ of the sample. Thirty-six per cent of the respondents indicated that their highest qualification is a master's degree in speech-language therapy.

Twelve of the respondents (55\%) have more than 15 years experience in the field, and another $18 \%$ have between 10 and 15 years of clinical experience. This indicated that all the respondents have sufficient knowledge and exposure in working with speech and language difficulties. Eighteen of the respondents' caseloads are comprised of less than 25\%, 3 of the respondents' caseloads are comprised of 25 $50 \%$, and only 1 respondent's caseloads are comprised of $50-75 \%$ of adolescents with written-language difficulties.

\section{Ethics}

The study abided by principles of research ethics by obtaining informed consent, adhering to anonymity and beneficence in terms of the research design, and ensuring the competency of the researchers. Informed consent was granted through submission of the questionnaire. Each questionnaire was numbered and no names were requested. Ethical clearance was obtained from the Faculty of Humanities, University of Pretoria, South Africa.

\section{Procedure}

A self-administered questionnaire (Appendix A) was chosen as the method of data collection. A pilot study was conducted prior to the data collection. Based on the feedback received from the respondents who participated in the pilot study, refinements to the questionnaire were made. A covering letter explaining the nature, content and aim of the research study was attached to the questionnaire. Respondents were informed that they were consenting to participate in the research study by completing the questionnaire, and that participation was voluntary.

A total of 100 questionnaires were distributed to all speechlanguage therapists on the 2009 SASLHA membership list via email. The SASLHA membership list is the most comprehensive database available of private-practising speech-language therapists in South Africa. However, it is recognised that not all private-practising speechlanguage therapists are SASHLA members, and therefore some amount of respondent bias could have occurred. Twenty-two questionnaires were returned via email. A response rate of $20-30 \%$ is seen as acceptable (Salkind, 2006). The monitoring of returns via email was carefully recorded by utilising a return rate graph, and follow-up mailings to non-respondents was an additional encouragement to participate (Irwin, Pannbacker, \& Lass, 2005).

\section{Analysis}

Data were analysed quantitatively as well as qualitatively. The study objectives were used to guide the analysis, and data were presented in tabular and graphical format using the computer spreadsheet program Microsoft Excel. A descriptive statistical analysis was used to synthesise and describe quantitative data (Irwin et al., 2005). Qualitative data were analysed by means of a content analysis. This process involved the categorising of responses obtained and placing these in a specific context. A descriptive statistical analysis was used to synthesise and describe quantitative data (Irwin et al., 2005). The objectives were used to determine which topics to include or exclude during the analysis. The number of responses associated with each theme was analysed statistically by determining the frequency patterns for each theme.

\section{Validity and reliability}

The goals of the research project were clearly specified in the cover letter. An in-depth literature study was conducted consulting recent and relevant research on assessment and intervention of isolated writtenlanguage difficulties in adolescents as well as long-term outcomes when disabilities are not addressed. Previous research questionnaires were reviewed and compared with the questionnaire used in this study, in order to ensure criterion validity. A range of questions were included in the questionnaire, e.g. open- and closed-ended questions, to ensure construct validity of a well-planned questionnaire (Irwin et al., 2005).

\section{Results and discussion}

Current practice of speech-language therapists in South Africa regarding the assessment and intervention of adolescent written-language skills

Practice regarding assessment

Most of the respondents (95\%) felt that existing assessment tools for assessment of written-language difficulties are insufficient. Furthermore, the respondents use more informal assessment tools (64\%) than formal tools (36\%), confirming this inadequacy. Examples of formal assessment tools used by the respondents are the Test of Word Reading Efficiency (TOWRE) (Torgesen, Wagner, \& Rashotte, 1999), Test of Written Language-2 (TOWL-2) (Hammill \& Larsen, 1988), Wechsler Objective Language Dimensions (WOLD) (Wechsler, 1996), and the Test of Adolescent Language (TOAL-4) (Hammill, Brown, Larson, \& Wederholt, 2007). Informal assessment tools were mainly indicated as informal written tasks, making use of the adolescents' school books and written class work and ability to formulate and write down answers. A few of the respondents were of the opinion that the existing assessment tools are not age appropriate $(8 \%)$ and many felt that they are culturally inappropriate (44\%).

A need exists for culturally valid and reliable developmental assessment tools for children with written-language difficulties that are able to accommodate multiple languages (Bornman, Sevcik, Romski, \& Pae, 2010). In South Africa the work of authors such as Bortz (1997) and Stark (2010) is a step in the right direction, but considerable work still needs to be done. Furthermore, linguistic bias by the therapist who administers the test, and bias toward life experience and social practices (Laing \& Kamhi, 2003) should be considered in a developing country which requires innovative initiatives grounded in knowledge of the challenges that characterise it.

\section{Practice regarding intervention}

Respondents mostly base their intervention on experience and not on previous research (Fig. 1). This indicates that relevant literature and research on intervention with adolescents of diverse linguistic and cultural backgrounds are limited. Examples of the different programmes and techniques used by a number of the respondents during intervention are indicated in Table 1.

\section{Successful intervention}

The respondents described the following factors as necessary for successful intervention:

- The child's motivation and the parent's support. Many respondents felt that the adolescent's will to succeed plays the biggest role in successful intervention. When the adolescent has a positive attitude and is willing to work with the therapist, improvement is more likely to occur. It is also important that parents provide support and understand the longterm advantages of speech-language therapists' services 
Table 1. Different programmes and techniques used by respondents

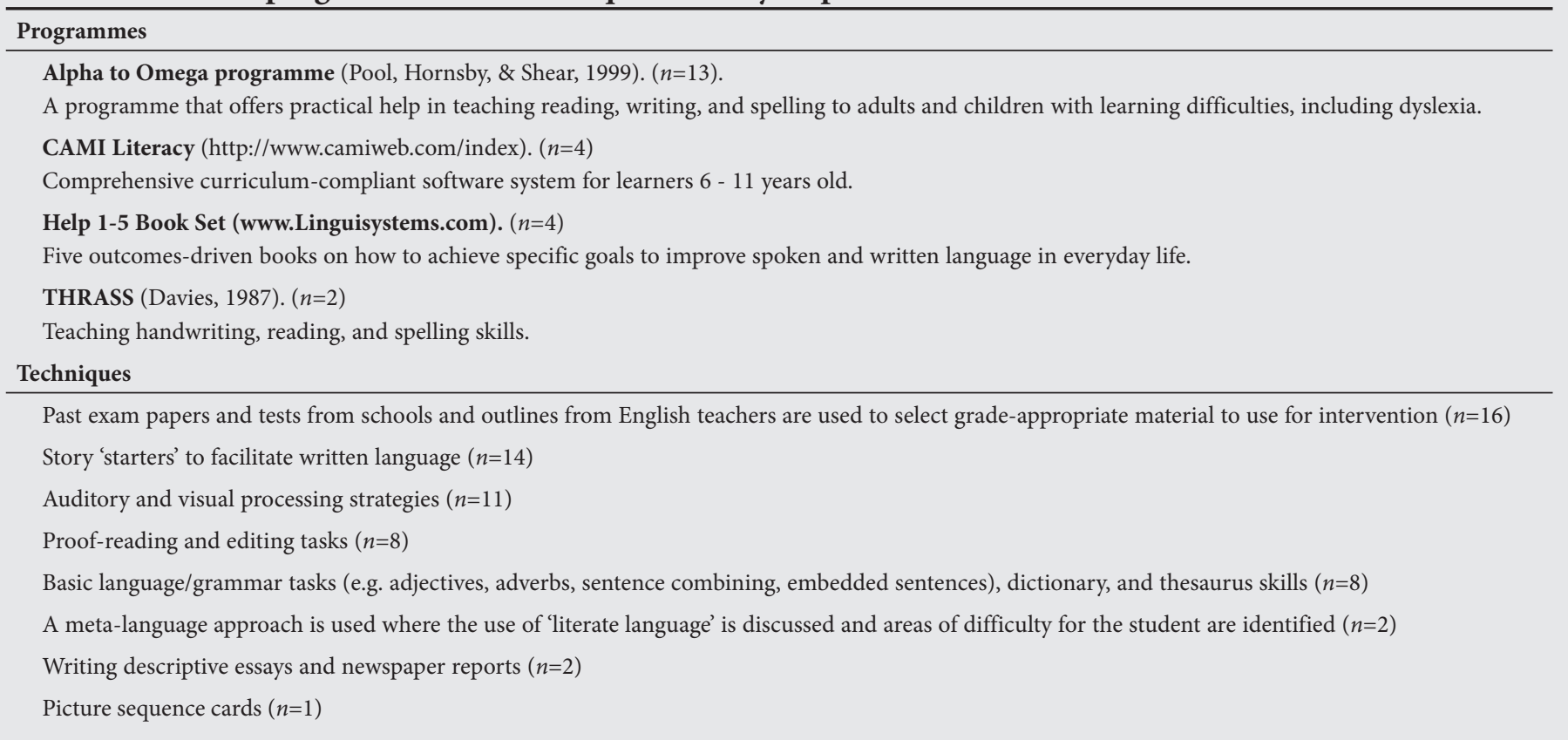

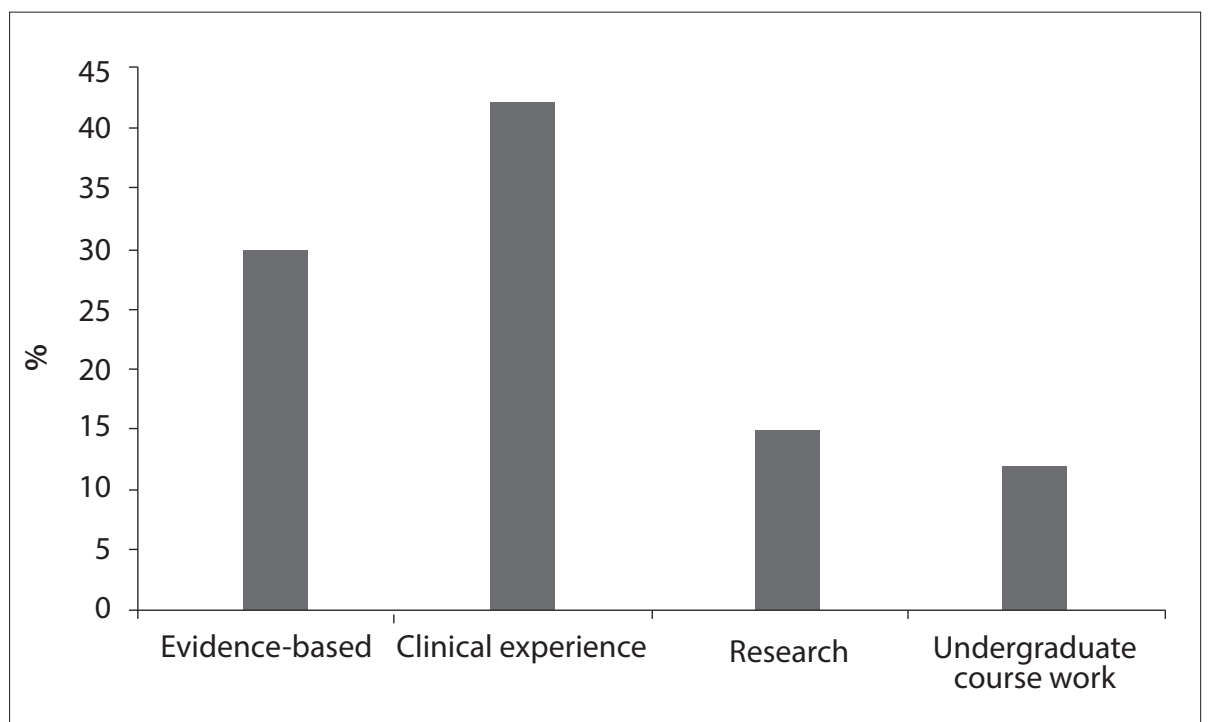

Fig. 1. Respondents' $(\mathrm{n}=22)$ intervention bases.

- Appropriate and consistent therapy programmes. Respondents commented that consistent intervention, that is relevant to the adolescent's curriculum, is important. A client-based programme, which specifically meets the needs of the individual, must be designed. One respondent commented that activities need to be fun, and that computerbased activities seem to interest adolescents. Another respondent commented that it is important for adolescents to see visible signs of their own progress in order to increase motivation.

- Improved understanding of written-language deficits. It is important that speechlanguage therapists understand and identify underlying deficits of written-language disabilities. One respondent mentioned that written-language difficulties, which may not have been identified early, do not necessarily resolve and therefore require the resumption of therapy in the adolescent difficulties are often identified at a late stage. Some respondents are of the opinion that adolescents with written-language difficulties are often labelled as having poor cognitive abilities, and are then referred for remedial education. Other respondents feel that written-language difficulties are still diagnosed as a learning problem and referred to remedial programmes where the focus is on grammar and spelling, and not on the language used in writing.

- Limited appropriate material. This is not only a challenge during assessment, but also during intervention. Most of the respondents (95\%) were of the opinion that the available treatment tools are culturally inappropriate. Some respondents (82\%) also felt that they have inadequate training and exposure in the use of available tools for intervention. Respondents mentioned an insufficient number of effective programmes and a lack of intervention tools incorporating aspects of the school curriculum. The ever-present additionallanguage challenge impacting on effective treatment was highlighted.

- Adolescents themselves. Motivation on the side of the client may be the most apparent barrier. Clients' lack of interest and lack of self-confidence poses a problem during intervention. The respondents identified numerous constraints, such as adolescents having limited time to attend and follow through with the intervention programmes, as well as limited financial resources.

The greatest challenge identified by the respondents regarding intervention for this population was the lack of sufficient assessment and intervention tools. The fact that speech-language therapists are not adequately trained at undergraduate level in this area was also mentioned. The respondents considered the client's motivation and parent 
support to be the most important additional contributor to successful intervention. This correlates with the self-determination theory which suggests that students' motivation for academic tasks varies in both strength and quality, and both strength and quality predict learning, achievement, and continuation to tertiary education (Hardré \& Reeve, 2003)

\section{Perceptions of speech-language therapists in South Africa regarding their role in assessment and intervention of adolescent written-language difficulties}

A majority of the respondents (86\%) indicated that they felt that speech-language therapists are not adequately involved when it comes to the identification, assessment and intervention of written-language difficulties in adolescents. However, they do feel they have a role to play in these processes. Speechlanguage therapists may be reluctant to assume roles regarding reading and writing for a variety of reasons such as: their own perceptions, fear of change and lack of training (Ehren \& Ehren, 2001). According to our findings, South African private-practising speech-language therapists are aware that identification, assessment and intervention of adolescents with written-language difficulties are within the scope of practice of the speechlanguage therapist.

\section{Perception regarding assessment}

A majority of the respondents (86\%) felt that speech-language therapists in South Africa are insufficiently active and involved in the assessment of adolescents with writtenlanguage difficulties. Fourteen respondents (64\%) indicated that they feel responsible for identification of adolescents with writtenlanguage difficulties together with other professionals. These professionals include: teachers, occupational therapists, remedial teachers, neuro-psychologists, educational psychologists and clinical psychologists.

\section{Perception regarding intervention}

A majority of the respondents (82\%) reported that speech-language therapists in South Africa are insufficiently active in providing treatment to adolescents with written-language difficulties. Only $18 \%$ of the respondents indicated that they feel solely responsible. Twelve (55\%) indicated they are responsible as part of a multiprofessional team. Six respondents $(27 \%)$ felt that they had no role to play during intervention in writtenlanguage difficulties in this population.

\section{Needs in future training regarding assessment and intervention for adolescent written-language difficulties}

Ten (45\%) respondents felt adequately equipped to provide intervention to adolescents with written-language difficulties. Some indicated they felt this way because of experience, self-study and secondary training. On the other hand, 8 respondents

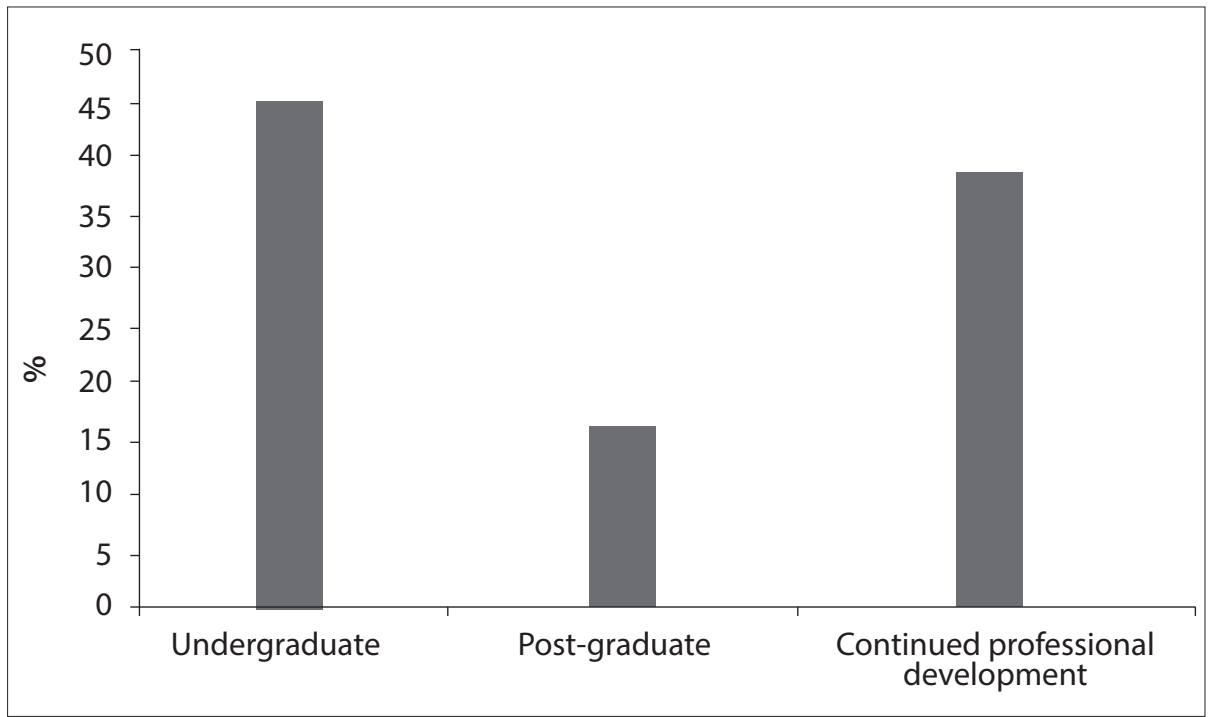

Fig. 2. Respondents' $(\mathrm{n}=22)$ perceptions regarding necessary level of training.

(36\%) stated that they felt poorly equipped to provide intervention to this population. Ten (45\%) respondents also felt that training in intervention of written-language difficulties in adolescents should be taking place at an undergraduate level. The respondents specifically stated that training with regard to collaboration with teachers is needed, as well as training in the provision of information to educators in order for them to make appropriate referrals and accommodations in the classroom. There is increasing awareness of the need for collaboration between speechlanguage therapists and professionals in the secondary educational setting (Vance \& Clegg, 2010). Most respondents also felt that the greatest need in providing intervention to adolescents with written-language difficulties lay in the area of assessment. Training needs at different levels of education can be summarised as follows:

\section{Undergraduate}

Of the 22 respondents, 14 (64\%) indicated that their highest qualification is an undergraduate degree in speech-language therapy. One of these indicated that $\mathrm{s} /$ he did not feel equipped to provide intervention, and another indicated that $s /$ he is well equipped. Half indicated that they feel adequately equipped to provide intervention; however, $36 \%$ indicated that they feel poorly equipped to do so.

\section{Masters}

Eight (36\%) respondents indicated that their highest qualification is a master's degree in speech-language therapy. Equal numbers of these respondents felt sufficiently and insufficiently equipped to provide intervention for written-language difficulties. Some of the respondents who indicated feeling adequately equipped did not feel equipped through primary training, but as a result of experience, self-study and secondary training in the field of remedial education.

Figure 2 indicates the respondents' perceptions regarding the expected level of training necessary for assessment and intervention for adolescents with writtenlanguage difficulties.

In summary, most respondents (86\%) indicated that they felt the greatest overall need in written-language difficulties in adolescents lay in the area of assessment by speech-language therapists. The South African context, the need for standardised tools in the various languages, and the need for culturally and linguistically valid tools, as well as more affordable tools, were stressed throughout. The need for specific guidelines when working with adolescents with writtenlanguage difficulties was mentioned, as well as a need for information on the curriculum of secondary school students, and what is expected of them academically.

A previous study reported that classroom teachers are the team members who are most familiar with the educational curriculum and are most responsible for ensuring that it is presented (Geertsema et al., 2011). On the other hand, speech-language therapists are also key role players in the modification, adaptation, and individualisation of this curriculum (Elksnin \& Capilouto, 1994). It is therefore essential that confidence and trust be established among educators and speech-language therapists when educating children in the classroom (Ferguson, 1992). The need for information on the influence of language impairment on written language was additionally identified as a possible contributory factor to the uncertainty surrounding the assessment and treatment of the adolescent population.

\section{Summary and conclusion}

According to ASHA (2001) and SASHLA (2013), assessment of and intervention for adolescents with written-language difficulties fall within the role of the speechlanguage therapist. Educators agree that this population is the responsibility of speechlanguage therapists (Geertsema et al., 2011). The findings of the study indicate that the respondents are aware that this is their role, and that they should be actively involved in 
the identification of, assessment of and intervention for adolescents with written-language difficulties; however, they feel that speechlanguage therapists in general are not actively involved in identification, assessment and intervention in this population. The majority of the respondents feel that they are adequately equipped to work with adolescents with written-language difficulties; however, this is based on own experience, self-study and secondary training. Training regarding assessment of and intervention with adolescents with written-language difficulties needs to take place at an undergraduate level. There is also a need for training regarding effective collaboration with teachers, including the provision of information to teachers in the secondary educational setting - which is a depicted role of the speech-language therapist (Owens, 2010). The current practice of speech-language therapists involves mostly assessment with informal assessment tools, indicating that current assessment tools are not sufficient, ageappropriate or culturally sensitive. The current situation in South Africa is that school pass rates have dropped from a $60 \%$ average to about a $40 \%$ average in rural areas (Naki, 2010). This highlights the importance of our role as speech-language therapists in a collaborative relationship with educators (Geertsema et al., 2011). Further research is needed in developing appropriate assessment and intervention tools, as well as improvement of training at an undergraduate level.

\section{Implications}

The current study yielded a small sample size and focused only on speech-language therapists in private practice in South Africa. However, the preliminary results could have long-term implications for undergraduate and postgraduate degree studies, continuous professional development programmes, and similar studies on a larger scale in South Africa. Should an additional training programme be developed, the data obtained could be used to address the perceptions and needs of speech-language therapists regarding assessment and intervention of adolescents with written-language difficulties, e.g. the development of linguistically and culturally valid assessment material, broadening the theoretical knowledge base on the adolescent population in general, and collaborative practices within the educational system. The adolescent population in the current South African education system has been identified as having extensive literacy problems within a system that seems to have failed them (Naki, 2010). Optimal intervention should therefore be provided by the South African speech-language therapist as part of a team of professionals. Speech-language therapists should be optimally equipped to provide intervention for adolescents with written-language difficulties.

\section{Recommendations for further research}

The involvement and role of other professionals working with adolescents with written-language difficulties could be researched in the future. The effectiveness of collaboration between different professionals during assessment of and intervention with adolescents with written-language difficulties should also be evaluated. In-depth research focusing on the assessment and intervention materials currently used by speech-language therapists should be conducted. Specific assessment tools and programmes should be evaluated regarding their appropriateness for the South African context. There is currently a lack of research regarding adolescents and adults with written-language difficulties and how they cope in the educational and vocational settings. This is a topic for future research.

\section{References}

Adams, C. (2002). Practitioner review: The assessment of language pragmatics. J Child Psychol Psychiatry, 43, 973-988. doi:10.1111/1469.0026

American Speech-Language-Hearing Association. (2001). Roles and responsibilities of speechlanguage pathologists with respect to reading and writing in children and adolescents (Position Statement). Retrieved 18 August 2013 from www.asha.org/policy.

Bercow, J. (2008). The Bercow report: A review of services for children and young people (0-19) with speech-language and communication needs. Nottingham: DCSF Publications.

Bornman, J., Sevcik, R. A., Romski, M., \& Pae, H. (2010). Successfully translating language and culture when adapting assessment. Journal of Policy and Practice in Intellectual Disabilities, 7(2), 111-118. doi:10.1111/j.1741-1130.00254.x

Bortz, M. (1997). South African language assessments manual. Northumberland: STASS Publications.
Davies, A. (1987). THRASS: Teaching handwriting, reading and spelling skills. London, Collins Educational.

Department of Basic Education. (2010, p. 4). Notice 752 of 2010. Pretoria: Department of Basic Education.

Ehren, B. J., \& Ehren, T. C. (2001). New or expanded literacy roles for speech-language pathologists: Making it happen in the schools. Semin Speech Lang, 22(3), 233-244. doi:10.1055/1-2001-16146

Elksnin, L., \& Capilouto, G. (1994). Speech-language pathologists' perceptions of integrated service delivery in school settings. Language, Speech, and Hearing Services in Schools, 25 , 258-267.

Ferguson, M. (1992). Implementing collaborative consultation: An introduction. Language, Speech, and Hearing Services in Schools, 23, 361-362.

Geertsema, S., Hyman, C., \& Van Deventer, C. (2011). SMS language and written language problems: Educators' perspectives. South African Journal of Education, 31(4), 475-487.

Hammill, D. D., Brown, V. L., Larson, S. C., \& Wederholt, J. L. (2007). Test of adolescent language (4th ed). East Moline, IL: LinguiSystems.

Hammill, D. D., \& Larsen, S. C. (1988). Test of written language (2nd Ed.), Austin, Tx: PROEd.

Hardre, L., \& Reeve, J. (2003). A motivational model of rural students' intentions to persist in versus drop out of high school. Journal of Educational Psychology, 95(2), 347. doi:10.1037/0022-0663.95.2.347

Harreveld, B., Baker, K., \& Isdale, L. (2008). Teachers' work in reading literacy across the curriculum in the senior phase of learning. Curriculum Journal, 19(2), 105-118. doi:10.1080/09585170802079538

Irwin, D. L., Pannbacker, M., \& Lass, N. J. (2005). Clinical research methods in speechlanguage pathology and audiology (1st Ed.). San Diego: Plural Publishing.

Jantzen, C. (2010). Dyslexia: Learning disorder or creative gift? (2nd Ed.). Chippenham, Wiltshire: CPI Antony Rowe.

Jordaan, H. L. (2011). Language teaching is no panacea: A theoretical perspective and critical evaluation of language in education within the South African context. South African Journal of Communication Disorders, 58(2),79-85.

Kathard, H., Ramma, L., Pascoe, M., Jordaan, H. L., Moonsamy, S., Wium, A-M., Du Plessis, S., Pottas, L., Khan N. B. (2011) How can speech-language therapists and audiologists enhance language and literacy outcomes in South Africa? (And why we urgently need to). South African Speech-Language-Hearing Association, 2011-12. South African Journal of Communication Disorders, 58(2), 59-71.

Laing, S. P., \& Kamhi, A. (2003). Alternative assessment of language and literacy in culturally and linguistically diverse populations. Language, Speech, and Hearing Services in Schools (34)44-55. doi:10.1044/0161-1461(2003/005)

Moodley, S., Chetty, S., \& Pahl, J. (2005). The school-based speech-language therapist: choosing multicultural texts. South African Journal of Communication Disorders, 52, 40-50.

Moore, D. W., Bean, T. W., Birdyshaw, D., \& Rycik, J. A. (1999). Adolescent literacy: A position statement for the commission on adolescent literacy of the International Reading Association. Retrieved 18 August 2013 from www.reading.org/downloads/positions/ ps1036_adolescent.pdf

Naki, E. (2010, July 06). South African pupils to learn in first language. Retrieved 22 August 2010 from apnews.excite.com/article/20100706/D9GPN3CG2.html.

Owens, R. E. (2010). Language disorders: A functional approach to assessment and intervention (5th ed.). Boston: Pearson.

Pijper, N. C. (2003). The phonological awareness, written spelling and oral reading of learners in an inclusive English-medium education setting. Unpublished Master's dissertation University of Pretoria.

Rescorla, L. (2008). Age 13 language and reading outcomes in late-talking toddlers. J Speech Lang Hear Res, 48, 459-472. doi:10.1044/1092-4399 (2005/031)

Salkind, N. J. (2006). Exploring research. Upper Saddle River, NJ: Pearson Education.

SASHLA. (2013). South African Speech-Language-Hearing Association Position Statement Retrieved 18 August 2013 from www.sashla.org.

Schumaker, J. B., \& Deshler, D. D. (2003). Can students with LD become competent writers? Learning Disability Quarterly, 26(2), 129-141. doi:10/2307/1593595

Seeff-Gabriel, B. (2003). Phonological processing: A platform for assisting second-language learners with English spelling. Unpublished Master's dissertation: University of Pretoria.

Sitlington, P. L. (2008). Students with reading and writing challenges: Using an informal assessment to assist in planning for the transition to adult life. Reading \&Writing Quarterly, 24(1), 77-100.

Stark, S. (2010). Disleksie. Vereeniging: Prestige Art Press.

Staskowski, M. \& Creaghead, N. A. (2001). Reading comprehension: Language intervention target from early childhood through adolescents. Semin Speech Lang, 22(3), 185-196. doi:10.1055/s-2001-16198

Torgesen, J., Wagner, R. \& Rashotte, C. (1999). Test of Word Reading Efficiency (TOWRE). Torrance, CA: Western Psychological Services.

Vance, M., \& Clegg, J. (2010). Editorial note: Research and practice in the language and communication needs of adolescents in secondary education. Child Language Teaching and Therapy, 26(2), 101-102. doi:10.1177/0265659010366503

Wechsler, D. (1996). Wechsler Objective Language Dimensions. Upper Saddle River, NJ: Pearson Education.

Wellman, L. (2006). Teachers' and speech-language pathologists' definition of reading and perceived roles of school-based speech-language pathologists: Relationships to teacher referral practices. (dissertation). Retrieved from https://etd.ohiolink.edu/ 


\section{APPENDIX A}

\section{Questionnaire}

Speech-language therapy to adolescents with written language difficulties: Current practice, perceptions and needs regarding training in the South African context

Aim: The main aim of this study is to describe the services provided by private-practising speech-language therapists in South Africa with regard to the isolated written language difficulties in adolescents. The speech-language therapists' perceptions regarding their role need of training will also be investigated.

Informed consent: By completing this questionnaire, informed consent is granted to participate in this study. It is also assumed that the cover letter outlining the goals of this study, the participant's rights and ethical considerations related to the current study, have been read.

According to Owens (2004), written-language difficulties can be further categorised into dyslexia, which is a disorder of reading characterised by poor reading comprehension or word recognition abilities, and dysgraphia, which is a difficulty in writing including spelling errors, punctuation, word omissions, agrammatical sentences, substitution and lack of organisation (Englert \& Thomas, 1987).

Respondent number:

Please answer all the questions.

Please mark the appropriate option(s) with an $\mathrm{X}$ or by answering the questions in the space provided.

\section{Section 1: Biographical information.}

At which University did you obtain your qualification?

a. University of Pretoria

b. University of the Witwatersrand

c. University of KwaZulu-Natal

d. University of Stellenbosch

e. University of Limpopo

f. University of Cape Town

g. Other

1.2 For how long have you been practising as a speech-language therapist?
a. 0 - 2 years
b. 2 - 5 years
c. 5 - 10 years
d. 10 - 15 years
e. More than 15 years

1.3 Please indicate the highest qualification that you have obtained:
a. Undergraduate in Speech-Language Pathology
b. Masters

c. Doctoral

1.4 What percentage of adolescents with isolated written difficulties 1s your caseload currently comprised of?
a. Less than $25 \%$
b. $25-50 \%$
c. $50-75 \%$
d. $75 \%-100 \%$

Section 2: Perceptions regarding the role of the speech-language therapists in isolated written language difficulties of adolescents.

2.1 Do you play a role in the identification of adolescents with isolated written-language difficulties?

a. Yes, I am solely responsible.

b. Yes, I am responsible together with other professionals

c. No.

2.1.1 If you have answered $b$, please indicate which professionals are also involved:

2.2 Do you play a role in assessment of adolescents with isolated written-language difficulties?

a. Yes, I am solely responsible.

b. Yes, I am responsible together with other professionals

c. No, I am not responsible.

2.2.1 If you have answered b, please indicate which professionals are also involved: 
2.3 Do you play a role in intervention with adolescents with isolated written-language difficulties?

a. Yes, I am solely responsible.

b. Yes, I am responsible together with other professionals.

c. No, I am not responsible.

2.3.1 If you have answered $b$, please indicate which professionals are also involved:

Section 3: Perceptions regarding the needs of the speech-language therapist in written language difficulties of adolescents.

3.1 Do you feel that you are adequately equipped to provide intervention to adolescents with written-language difficulties?

a. Not equipped

b. Poorly equipped

c. Adequately equipped

d. Well equipped

e. Do not know

Comments:

2.4 In your opinion, how actively are speech-language therapists involved in the:

2.4.1 Identification of adolescents with written-language difficulties?

a. Actively

b. Sufficiently

c. Insufficiently

d. Not at all

2.4.2 Assessment of adolescents with written-language difficulties?

a. Actively

b. Sufficiently

c. Insufficiently

d. Not at all

2.4.3 Intervention with adolescents with written-language difficulties?

a. Actively

b. Sufficiently

c. Insufficiently

d. Not at all

3.2 In your opinion, at which level(s) should speech-language therapists be trained to assess and provide intervention to adolescents with written-language difficulties?

a. Undergraduate

b. Postgraduate

c. Continued professional development

3.3 In your opinion, what is the greatest need in the area of written-language difficulties in adolescents?

Comments:

Section 4: Evaluation/Assessment.

4.1 In your opinion, are there enough tools for the assessment of written language of adolescents in the South-African context?

a. Yes

b. No

4.2 Please indicate what types of assessment tools you are using to assess the written-language difficulties of adolescents?

a. Formal

b. Informal

Example(s):

4.3 If formal tools are used, are these tools age-appropriate?

a. Yes

b. No

c. Partly

4.3 Are the tools that you are using culturally sensitive?

a. Yes

b. No

c. Partly 


\section{Section 5: Intervention.}

5.1 On what do you base your intervention approach? (You may choose more than one option.)

a. Evidence-based

b. Clinical-experience

c. Research

d. Undergraduate course work

5.2 If you provide intervention to adolescents with written-language difficulties, please describe the techniques or programmes you find useful.

Comments:

5.3 In your opinion, what are the barriers experienced regarding effective interventions with adolescents with written-language difficulties?

Comments:

5.4 In your opinion, what are factors contributing to successful intervention with adolescents with written-language difficulties?

Comments: 